До вивчення явища фотоефекту та його законів у курсі фізики в середніх навчальних закладах

УДК 373.5.016:53

\title{
ДО ВИВЧЕННЯ ЯВИЩА ФОТОЕФЕКТУ ТА ЙОГО ЗАКОНІВ У КУРСІ ФІЗИКИ В СЕРЕДНІХ НАВЧАЛЬНИХ ЗАКЛАДАХ
}

\section{Олег Войнов}

учитель фізики астрономії й інформатики,

Миколаївський заклад загальної середньої освіти I-III ступенів № 3

Миколаївської міської ради Слов'янського району Донецької області Україна

bytic2010@gmail.com

Олександр Бєлошапка

старший викладач кафедри фізики

ДВНЗ «Донбаський державний педагогічний університет»

м. Слов'янськ, Донецька область, Україна

beloshapka78@ukr.net

Анотація. У статті розглядається вивчення фотоефекту і його законів у курсі фізики в середніх навчальних закладах. Автори пропонують матеріал 3 цієї теми, який можна використовувати на уроках, і наголошують, що вивчення окресленого явища $є$ основою для розуміння принципу дії й застосування різних фотоелектронних пристроїв у сучасній електроніці й техніці. Опрацювання теоретичних відомостей про фотоефект й розуміння його законів дозволяє розглянути поняття «корпускулярно-хвильового дуалізму світла» й матерії загалом.

Актуальність і важливість теми, на думку авторів, полягає в тому, що квантова фізика викладається в 11 класі: на завершальному етапі вивчення фізики. Саме розділи квантової фізики формують в учнів цілісну картину світу й завершують формування світогляду учнів.

Ключові слова: фотоефект; кванти світла; фотон; закони фотоефекту; рівняння Ейнштейна; квантова фізика; квантова теорія; робота виходу.

Постановка проблеми в загальному вигляді. Фізика дає нам розуміння того, що нас оточує, дозволяє зрозуміти процеси й закони, що відбуваються в природі. 3 погляду викладання, квантова фізика важлива тим, що в ній формуються основні квантові поняття, закономірності й створюється база для викладу навчального матеріалу наступних розділів: статистичної фізики, фізики твердого тіла тощо.

Основні пізнавальні завдання розділу «Квантова фізика» - ознайомити учнів зі специфічними законами, що діють в області мікросвіту, і завершити формування уявлень про будову речовини, що почала формувати базова школа, а також формування культурної компетенції й наукового світогляду учнів, ознайомити учнів із сучасною електронною технікою й основами сучасних технологій.

Аналіз основних досліджень і публікацій. Аналіз робіт С. Каменецкого, О. Бугайова, Є. Коршака, С. Гончаренко, М. Садового та інших дослідників дозволив виділити найбільш важливі, із погляду змісту й методики навчання 
До вивчення явища фотоефекту та його законів у курсі фізики в середніх навчальних закладах

фізики, проблеми становлення й розвитку квантових уявлень в учнів при вивченні квантової фізики та фізики атома й атомного ядра.

Під час викладу матеріалу «Фотоефект і його застосування» автори наявних підручників (напр.: В. Бар'яхтар, Ф. Божинова та ін. «Фізика 11». Академічний і профільний рівень. Видавництво «Ранок», 2011 р.) зазначають, якщо пластина заряджена позитивно, випущені електрони притягаються до пластини й вертаються назад, тому заряд електрометра не змінюється. Однак у цьому випадку електрон не може покинути метал, тому що він буде захоплений сусідніми іонами, а, отже, фотоефект не виникає.

Крім того, при поясненні існування фотоструму при нульовій напрузі не вказується наявність кінетичної енергії електронів, що вийшли, замість цього мова йде про залишкову (початкову) їхню швидкість.

При викладі матеріалу не вказуються всі основні протиріччя, які виникають під час пояснення фотоефекту за допомогою хвильової теорії світла, і їхнє пояснення квантовою теорією.

Формулювання цілей статті (постановка завдання). Метою статті $є$ визначення проблеми єдності й суперечливості квантових фізичних процесів і явищ у пізнанні мікросвіту під час вивчення фізики й визначення конкретного змісту навчального матеріалу, із яким варто познайомити учнів при вивченні явища фотоефекту та його законів як прикладу проявлення квантових властивостей світла.

Результати дослідження. Автори пропонують матеріал із теми: «Фотоелектричний ефект. Закони фотоефекту. Теорія фотоефекту, який можна використовувати під час вивчення цієї теми».

Фотоелектричний ефект. Закони фотоефекту. Теорія фотоефекту. Рівняння Ейнштейна для фотоефекту.

1. Повторення матеріалу.

1. Повторити з раніше вивченого матеріалу електромагнітні хвилі, умови найбільш ефективного випромінювання електромагнітних хвиль відповідно до електромагнітної теорії.

2. Які явища природи привернули увагу й викликали найбільший інтерес фізиків на початку XX століття після встановлення основних закономірностей поширення електромагнітних хвиль?

3. Які експериментальні факти були встановлені при вивченні теплового випромінювання нагрітого абсолютно чорного тіла? Що являє собою графік розподілу енергії в спектрі випромінювання абсолютно чорного тіла?

4. Як розподіляється енергія між різними довжинами хвиль у спектрі випромінювання абсолютно чорного тіла? Як змінюється характер її розподілу при зміні температури тіла?

5. Яке протиріччя виникає при спробі пояснення закономірностей розподілу енергії в спектрі теплового випромінювання за допомогою електродинаміки Максвелла й статистичної фізики? Чому ця ситуація одержала в науці назву «ультрафіолетова катастрофа»? 
До вивчення явища фотоефекту та його законів у курсі фізики в середніх навчальних закладах

6. Які факти, що є несумісними з досвідом і суперечать реальній дійсності, були отримані під час пояснення проблеми теплового випромінювання з погляду класичної фізики?

7. Як підійшов до розв'язання цієї проблеми М. Планк? У чому полягає гіпотеза Планка? Чому гіпотеза Планка про світлові кванти була не продовженням колишньої фізики, а ії̈ переворотом? У чому полягає значення цієї гіпотези для розвитку науки?

2. Вивчення нового матеріалу.

1. Розглянути явище фотоефекту, ознаки й умови протікання явища, описати експериментальну установку для спостереження фотоефекту.

Фотоефект був відкритий німецькими фізиками-експериментаторами В. Гальваксом і Г. Герцом у 1888 році. Було виявлено, що при освітленні негативно зарядженого провідника ультрафіолетовим світлом заряд провідника швидко зменшується. Фотоефект був докладно досліджений російським фізиком А. Столетовим у $1888-1890$ роках і трохи пізніше німецьким ученим Ф. Ленардом .

Фотоефект - ие вибивання електронів із речовини під дією світла. Якщо явище супроводжується виходом електронів за межі речовини, фотоефект називають зовнішнім, якщо не супроводжується - внутрішнім. У другому випадку він проявляється в зміні концентрації електронів та інших носіїв зарядів у різних частинах речовини, змінюючи його електричні й оптичні властивості.

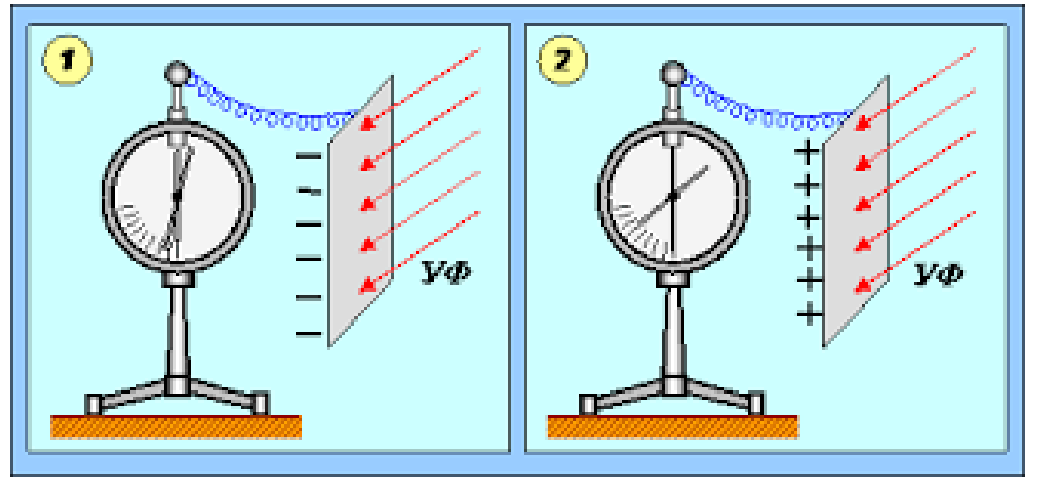

Рис.1. Зовнішній і внутрішній фотоефект

Досвіди підтверджують, що під дією енергії світлової хвилі вибиваються електрони 3 негативно зарядженої металевої пластини. При позитивно зарядженій пластині електрони не вибиваються (заряд пластини зберігається). Крім того, саме ультрафіолетова частина спектра спричиняє взаємодію електромагнітних хвиль 3 електронами металу, тобто фотоефект викликає випромінювання високої частоти.

Відзначимо, що світло - це електромагнітна хвиля, а світло, що падає на поверхню металу, приносить із собою змінне електричне поле. У такому полі електрон у металі повинен виконувати коливання, а при досить великій амплітуді 
він може й вилетіти 3 металу, де його втримує сила притягання до позитивно заряджених часток.

2. Розглянути схему й особливості експериментальної установки для вивчення законів фотоефекту та відзначити основні закони фотоефекту.

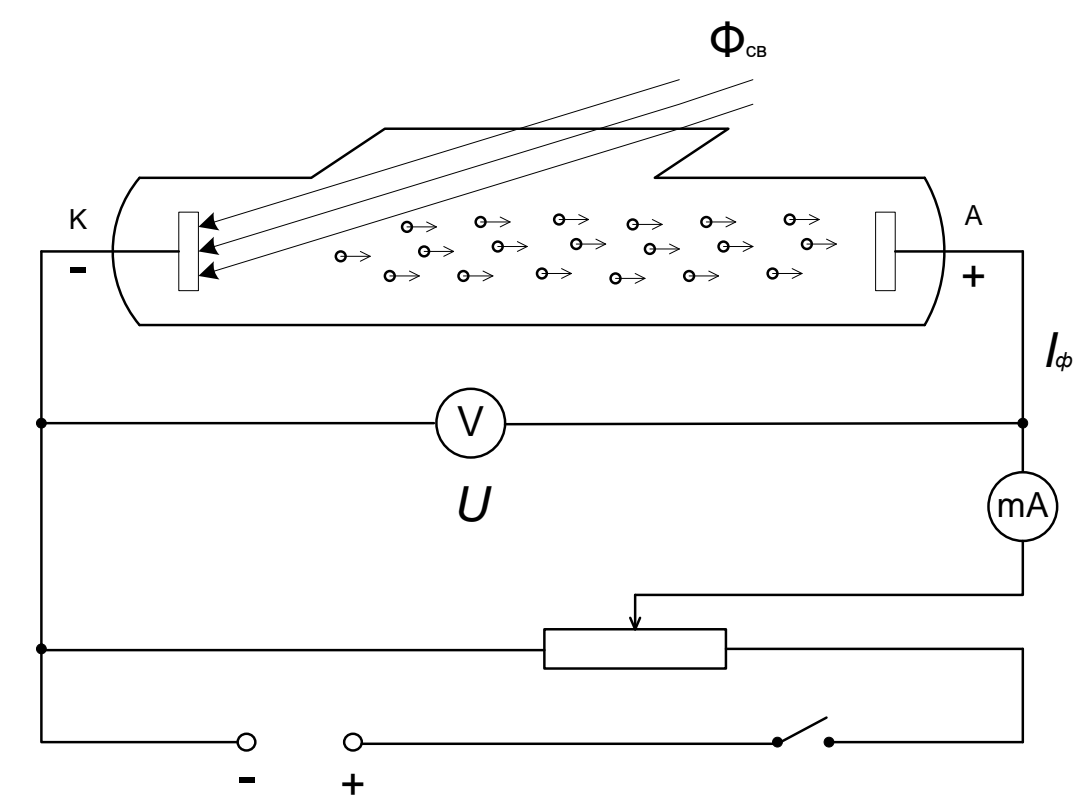

Рис. 2. Схема експериментальної установки для вивчення законів фотоефекту

1. Сила фотоструму $\mathrm{I}_{\phi}$ росте зі збільшенням напруги між електродами трубки, тому що зі збільшенням напруги зростає кількість електронів, що досягають анода; але при деякій досить великій напрузі $\mathrm{U}_{\text {н }}$ сила струму перестає зростати, тому всі електрони, що вибиті світлом, уже досягли анода й подальша їхня кількість не зростає зі збільшенням напруги.

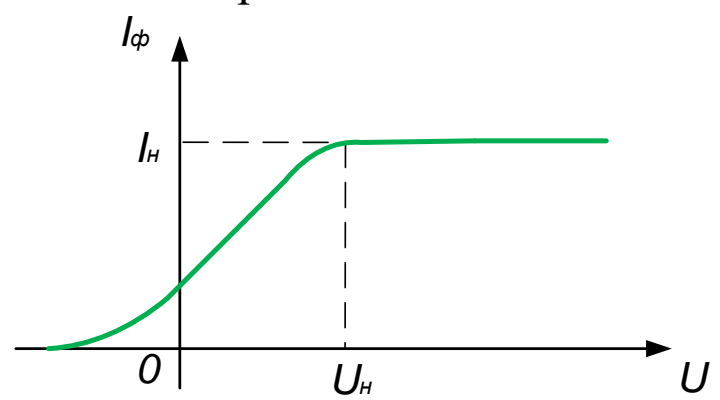

2. Сила фотоструму залежить від інтенсивності світла (світлового потоку). При збільшенні інтенсивності світла (світлової потужності лампи, світлового потоку й кількості світлової енергії) росте кількість світлової енергії, яка падає на катод, тому зростає кількість електронів, що вириваються світлом із поверхні металу за одну секунду й сила струму буде зростати; буде рости так само й струм насичення, причому при більшому світловому потоці струм насичення досягається при менших напругах. 


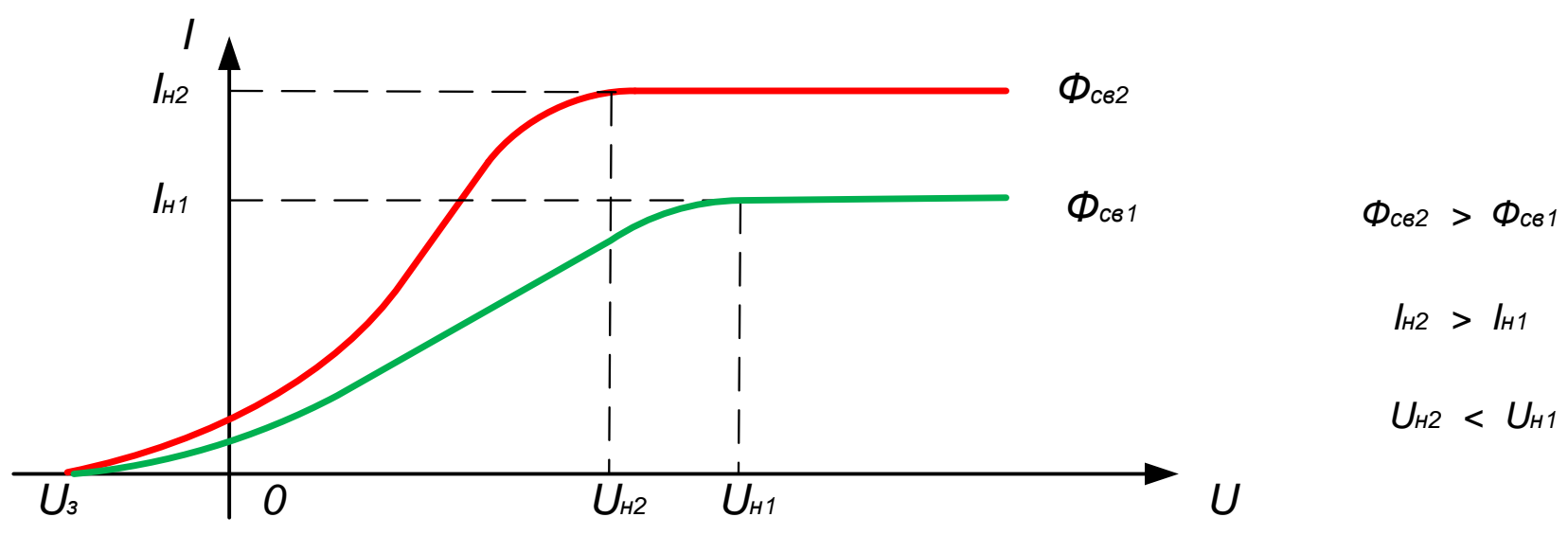

3. При нульовій напрузі в колі фотоелемента існує струм $(\mathrm{U}=0$; $\mathrm{I}_{\phi} \neq 0$ ), тому що частка найбільш швидких електронів, вирваних світлом, має достатню кінетичну енергію й досягає анода без надання їм додаткової енергії за рахунок електричного поля.

Щоб зменшити фотострум до нуля, потрібно для вирваних електронів створити гальмуюче електричне поле (змінивши полярність напруги на трубці), тоді всі вирвані світлом електрони втрачають свою енергію на подолання сил поля, тобто робота електричного поля йде на погашення кінетичної енергії електронів.

$$
\begin{array}{ll}
A_{9, n}=\Delta E_{\kappa} & A_{э л}=q U=-e \cdot U_{3} \quad \Delta E_{\kappa}=E_{\kappa 2}-E_{\kappa 1}=0-\frac{m v^{2}}{2}=-\frac{m v^{2}}{2} \\
-e \cdot U_{3}=-\frac{m v^{2}}{2} & e \cdot U_{3}=\frac{m v^{2}}{2}
\end{array}
$$

4. Затримуюча напруга не залежить від світлового потоку, тобто кінетична енергія, а значить і швидкість електронів, не залежить від інтенсивності світла. Вона залежить лише від частоти падаючого випромінювання.

Відповідно до хвильової теорії світла згідно 3 класичною електродинамікою зі збільшенням світлового потоку падаючого на катод (інтенсивності світла) повинна зростати енергія електронів, що вилітають, тому що зі збільшенням світлової енергії падаючої на пластину зростають сили, що діють на електрони металу. Так, зростає амплітуда їхніх змушених коливань в атомах, a, отже, прискорення й швидкість електронів. Отже, повинна зростати їхня кінетична енергія, а тому і затримуюча напруга. Зазначені факти зовсім не погоджуються з експериментом, тому класична хвильова теорія не може пояснити фотоефект.

5. Згідно з квантовою теорією фотоефект можна пояснити в такий спосіб: при збільшенні інтенсивності світла зростає кількість вирваних світлом електронів, тому і сила фотоструму, але їхня якість (швидкість, енергія) не змінюються при зміні інтенсивності світла. Отже, затримуюча напруга $\mathrm{U}_{3}$ теж не буде зміняться з ростом інтенсивності світла. 
У 1905 р. Альберт Ейнштейн запропонував теорію, що давала пояснення відразу всій сукупності експериментальних фактів про фотоефект. Розвинувши й поглибивши ідею М. Планка, А. Ейнштейн дійшов висновку, що світло повинно не лише випромінюватися й поглинатися, але й поширюватися у вигляді окремих порцій енергії: квантів електромагнітного поля (фотонів). Він уважав, що при взаємодії з речовиною фотон поводиться подібно частинці й передає свою енергію не речовині загалом і навіть не атому, а лише окремим електронам.

Відповідно до квантової теорії електрони не лише випромінюють, але й поглинають світлову енергію окремими порціями (квантами). Енергія кванта світла, що одержує електрон в атомі металу, визначається лише його частотою. Тому і його швидкість $v$, а значить і затримуюча напруга $\mathrm{U}_{3}$ повинні залежати лише від частоти світла. Це підтверджується експериментом.
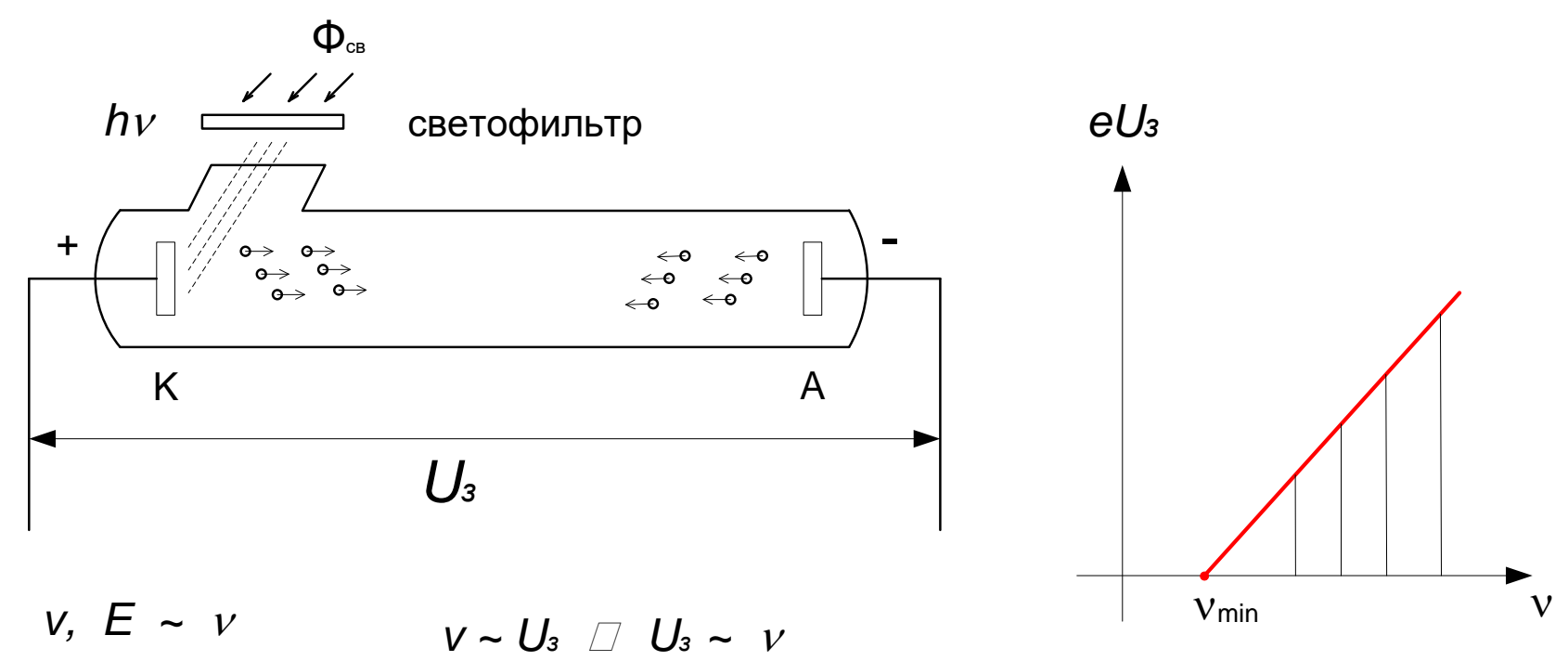

\section{6 г. Р.Милликен}

6. Світлова енергія може випромінюватися й поглинатися лише окремими порціями (квантами)

$$
E=h \cdot v \quad h=6,63 \cdot 10^{-34} \text { Дж} \cdot c \quad h \text { - постійна Планка }
$$

Енергія кванта світла, поглинена речовиною, йде на виведення електронів із речовини й надання їм кінетичної енергії.

Енергія, яку потрібно надати електрону, щоб вивести його з металу, називається роботою виходу електронів із металу $\mathrm{A}_{\text {вих }}$. Вона залежить лише від властивостей атомів металу й може бути визначена експериментально (для неї складені таблиці). 


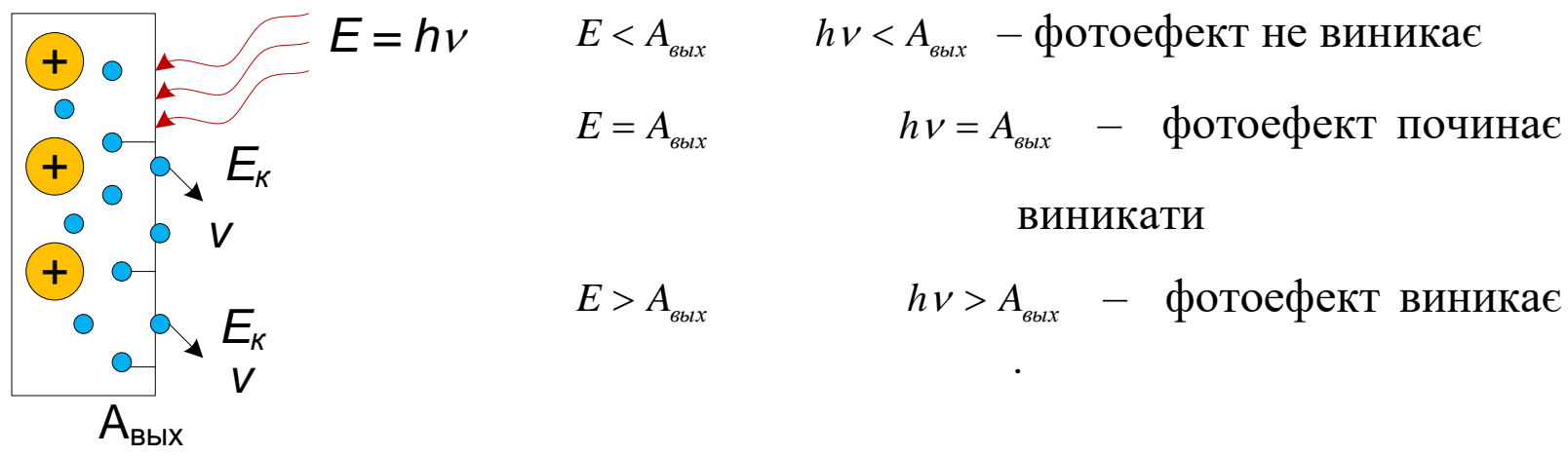

$$
E_{c в}=A_{\text {выx }}+E_{\kappa} \quad h v=A_{\text {выx }}+\frac{m v^{2}}{2}-\text { рівняння Ейнштейна для фотоефекту }
$$

7. Не всяке світло здатне вирвати електрони з металу. Для кожної речовини існує мінімальна частота $\left(v_{\min }\right)$ або максимальна довжина хвилі $\left(\lambda_{\max }\right)$, при якій виникає фотоефект. Вона називається червоною границею фотоефекту. Цій частоті відповідає мінімальна енергія кванта світла, що здатна викликати фотоефект.

$$
\begin{array}{ll}
h v_{\min }=A_{\sigma b l x} & v_{\min }=\frac{A_{6 b l x}}{h} \\
\lambda=c T=\frac{c}{v} & v=\frac{c}{\lambda} \quad v_{\min }=\frac{c}{\lambda_{\max }} \quad h \frac{c}{\lambda_{\max }}=A_{6 b l x}
\end{array}
$$

8. Класична й квантова теорії розходяться при оцінюванні часу початку виникнення фотоефекту. Відповідно до класичної теорії інтервал часу, упродовж якого електрон може накопити енергію, необхідну для свого звільнення з металу, повинен бути від декількох хвилин до декількох годин. Квантова теорія підтверджує, що фотон, який падає на метал, може дуже швидко звільнити 3 нього один електрон, якщо він володіє необхідною для цього енергією (частотою). Дані квантової теорії повністю підтверджуються експериментом.

3. Закріплення нового матеріалу.

1. Повторити основні найбільш важкі моменти досліджуваного матеріалу, навести короткі підсумки.

2. Розглянути типові питання на закріплення явища фотоефекту та його законів:

а) що являє собою явище фотоефекту й за допомогою яких найпростіших приладів можна демонструвати це явище?

б) надати опис установки для вивчення законів фотоефекту: із яких приладів вона складається і як вони включаються між собою?

в) як залежить сила струму в колі фотоелемента від прикладеної напруги? Що називають струмом насичення?

г) як залежить сила фотоструму в колі фотоелемента від інтенсивності світла, що падає на нього? Як пояснюється ця залежність? 
До вивчення явища фотоефекту та його законів у курсі фізики в середніх навчальних закладах

д) чому при нульовій напрузі в колі фотоелемента існує струм? Що називають затримуючою напругою?

е) яким чином можна визначити максимальну швидкість або кінетичну енергію електронів, що вилітають із катода?

ж) від чого залежить максимальна швидкість або кінетична енергія електронів, що вилітають із катода?

3) чому явище фотоефекту не може бути пояснене за допомогою хвильової теорії світла? Яким чином можна пояснити фотоефект завдяки квантовій теорії?

к) у чому складається розвиток гіпотези Планка запропонованої Ейнштейном?

л) як гіпотеза світлових квантів дозволяє пояснити фотоефект?

м) що представляє собою робота виходу електронів із металу та як можна визначити іiі величину?

н) записати рівняння Ейнштейна для фотоефекту? Які умови повинні бути виконані для виникнення фотоефекту?

о) що являє собою червона границя фотоефекту та яке значення цієї величини?

п) які основні протиріччя виникають при поясненні фотоефекту за допомогою хвильової теорії світла?

р) які експериментальні факти (явища природи), відомі вам, суперечать хвильовій теорії світла?

\section{4. Домашнє завдання}

Висновки $з$ дослідження і перспективи подальших розвідок у цьому напрямі. Вивчення окресленого явища $є$ основою для розуміння принципу дії й застосування різних фотоелектронних пристроїв у сучасній електроніці й техніці.

Вивчення фотоефекту й розуміння його законів дозволяє розглянути дуже важливе поняття «корпускулярно-хвильового дуалізму світла» й матерії загалом.

Важливість теми, на нашу думку, полягає в тому, що квантова фізика викладається в 11 класі: на завершальному етапі вивчення фізики. Саме розділи квантової фізики формують в учнів цілісну картину світу й завершують формування світогляду учнів.

\section{СПИСОК ВИКОРИСТАНИХ ДЖЕРЕЛ}

1. Савельев, И. В. (1987). Курс общей физики. Москва: Наука.

2. Гончаренко, С. У. (1995). Фізика. Київ, Україна: Освіта.

3. Сущенко, С. С. (2007). Викладання квантових властивостей світла у школі. Харків, Україна: Основа.

4. Коршак, С. В., Ляшенко, О. І. і Савченко, В. Ф. (2004). Фізика 11 клас. Київ, Україна: Ірпінь; ВТФ Перун.

5. Бар'яхтар, В. Г. і Божинова, Ф. Я. (2011).Фізика 11 клас. Академічний рівень. Профільний рівень. Харків, Україна: Відавництво «Ранок».

6. Збаратський, Д. О. (2015). Рівняння Енштейна. Кванти світла. Фізика в школах України, 5/6, 65-66. 


\title{
К ИЗУЧЕНИЮ ЯВЛЕНИЙ ФОТОЭФФЕКТА И ЕГО ЗАКОНОВ В КУРСЕ ФИЗИКИ В СРЕДНИХ УЧЕБНЫХ ЗАВЕДЕНИЯХ
}

\author{
Олег Войнов \\ учитель физики астрономии и информатики, \\ Николаевский заведение общего среднего образования I-III ступеней № 3 \\ Николаевского городского совета \\ Славянского района Донецкой области Украины \\ bytic2010@gmail.com \\ Александр Белошапка \\ старший преподаватель кафедры физики \\ ГВУЗ «Донбасский государственный педагогический университет» \\ г. Славянск, Донецкая область, Украина \\ beloshapka78@ukr.net
}

Аннотация. В статье рассматривается изучение фотоэффекта и его законов в курсе физики в средних учебных заведениях. Авторы предлагают материал по этой теме, который можно использовать на уроках, и подчеркивают, что изучение очерченного явления является основой для понимания принципа действия и применения различных фотоэлектронных устройств в современной электронике и технике. Разработка теоретических сведений о фотоэффект и понимание законов позволяет рассмотреть понятия «корпускулярно-волнового дуализма света» и материи в целом.

Актуальность и важность темы, по мнению авторов, заключается в том, что квантовая физика излагается в 11 классе: на завершающем этапе изучения физики. Именно разделы квантовой физики формируют у учащихся целостную картину мира и завершают формирование мировоззрения учащихся.

Ключевые слова: фотоэффект; кванты света; фотон; законы фотоэффекта; уравнения Эйнштейна; квантовая физика; квантовая теория; работа выхода.

\section{TO STUDYING THE PHENOMENON OF PHOTOELECTRIC EFFECT AND ITS LAWS IN THE COURSE OF PHYSICS IN SECONDARY SCHOOLS}

\author{
Oleh Voinov \\ Teacher of Physics, Astronomy and Computer Studies \\ Mykolaivka Secondary Comprehensive Institution_№ 3 of \\ Mykolaivka Town Council \\ Mykolaivka, Donetsk region, Ukraine \\ bytic2010@gmail.com \\ Oleksandr Bieloshapka \\ Senior Lecturer of Department of Physics \\ SHEE "Donbas State Pedagogical University" \\ Sloviansk, Donetsk region, Ukraine \\ beloshapka78@ukr.net
}

Abstract. The article addresses the issue of studying phenomenon of photoelectric effect and its laws in the course of Physics in secondary schools. This issue is relevant as Physics contributes to understanding processes and laws that take place in the nature. From the standpoint of teaching 


\section{ОЛЕГ ВОЙНОВ, ОЛЕКСАНДР БЄЛОШАПКА}

До вивчення явища фотоефекту та його законів у курсі фізики в середніх навчальних закладах

quantum physics is important because the main quantum concepts and laws are developed and database for storing learning materials of such sections as static physics, physics of solid body is being developed.

The authors analyses a number of researches that allow to point out the main problems of emergence and development of students' quantum view while studying quantum physics, physics of atom and atom core.

The article is aimed at defining the unity and contradictions of quantum physical processes and phenomena while learning microworld in the course of Physics and determining the content of learning activity that should be presented to students while studying phenomenon of photoelectric effect and its laws as an example of displaying quantum qualities of the light.

The authors suggest the materials of the theme 'Photoelectric effect', laws of photoelectric effect, theory of photoelectric effect that can be studied while teaching this theme. The learning content that is represented in the article can be applied for revising, studying and summarizing learning material. The article also contains the examples of tasks for homework. It can be concluded that the article has a great practical content that can be implemented in educational process of secondary comprehensive schools while teaching Physics.

Key words: photoelectric effect; light quants; photon; laws of photoelectric effect; Einstein equals; quantum physics; quantum theory.

\section{REFERENCES}

1. Savel'ev, I. V. (1987). Course of General Physics. Moscow: Nauka.

2. Honcharenko, S. U. (1995). Physics. Kyiv, Ukraine: Osvita.

3. Sushchenko, S. S. (2007). Teaching quantum properties of light at school. Kharkiv, Ukraine: Osnova.

4. Korshak, Ye. V., Liashenko, O. I., \& Savchenko, V. F. (2004). Physics Class 11. Kyiv, Ukraine: Irpin; VTF Perun.

5. Bariakhtar, V. H., \& Bozhynova, F. Ya. (2011). Physics Class 11. Academic level. Profile level. Kharkiv, Ukraine: Vidavnytstvo «Ranok».

6. Zbaratskyi, D. O. (2015). Equation of Enshtein. Quantums of light. Fizyka v shkolakh Ukrainy, 5/6, 65-66.

Матеріали надійшли до редакції 12.05.2018 р. 